\title{
Comparison of intervention effects in split-mouth and parallel-arm randomized controlled trials: a meta-epidemiological study
}

Violaine Smaïl-Faugeron ${ }^{1,2,3,7^{*}}$, Hélène Fron-Chabouis ${ }^{3,4}$, Frédéric Courson ${ }^{2,3}$ and Pierre Durieux ${ }^{1,5,6}$

\begin{abstract}
Background: Split-mouth randomized controlled trials (RCTs) are popular in oral health research. Meta-analyses frequently include trials of both split-mouth and parallel-arm designs to derive combined intervention effects. However, carry-over effects may induce bias in split- mouth RCTs. We aimed to assess whether intervention effect estimates differ between split- mouth and parallel-arm RCTs investigating the same questions.

Methods: We performed a meta-epidemiological study. We systematically reviewed meta- analyses including both split-mouth and parallel-arm RCTs with binary or continuous outcomes published up to February 2013. Two independent authors selected studies and extracted data. We used a two-step approach to quantify the differences between split-mouth and parallel-arm RCTs: for each meta-analysis. First, we derived ratios of odds ratios (ROR) for dichotomous data and differences in standardized mean differences ( $\triangle S M D)$ for continuous data; second, we pooled RORs or $\triangle S M D$ s across meta-analyses by random-effects meta-analysis models.

Results: We selected 18 systematic reviews, for 15 meta-analyses with binary outcomes ( 28 split-mouth and 28 parallel-arm RCTs) and 19 meta-analyses with continuous outcomes (28 split-mouth and 28 parallel-arm RCTs). Effect estimates did not differ between split-mouth and parallel-arm RCTs (mean ROR, 0.96, 95\% confidence interval 0.52-1.80; mean $\triangle S M D, 0.08,-0.14-0.30)$.

Conclusions: Our study did not provide sufficient evidence for a difference in intervention effect estimates derived from split-mouth and parallel-arm RCTs. Authors should consider including split-mouth RCTs in their meta-analyses with suitable and appropriate analysis.
\end{abstract}

Keywords: Meta-analysis, Randomized controlled trial, Split-mouth trial, Bias, Meta-epidemiological study

\section{Background}

In split-mouth randomized controlled trials (RCTs) in oral health, experimental and control interventions are randomly allocated to different areas in the oral cavity (teeth, surfaces, arches, quadrants) [1-3]. As compared with parallel-arm RCTs, split-mouth RCTs have the advantage that most of the variability of outcome among patients is removed from the intervention effect estimate for a potential increase in statistical power, each subject being its own control [4,5]. Because every

\footnotetext{
* Correspondence: violaine.smail-faugeron@parisdescartes.fr

'Institut National de la Santé et de la Recherche Médicale, U1138, Equipe 22,

Centre de Recherche des Cordeliers, Paris, France

${ }^{2}$ Assistance Publique-Hôpitaux de Paris, Hôpital Bretonneau, Service

d'Odontologie, Paris, France

Full list of author information is available at the end of the article
}

subject receives each intervention, the design may also be better suited to determine patient preferences.

Many researchers in oral health research use the split-mouth design. Therefore, systematic review authors frequently include trials of both split-mouth and parallelgroup designs to derive combined intervention effects. The rationale to include split-mouth RCTs is to use all the available evidence. However, the split-mouth design may lead to biased intervention effect estimates. For instance, carry-over effects (ie, contamination or "spilling" of the effects of one intervention from one site to another site) may induce bias in split-mouth RCTs [4]. If the interventions are delivered at different times, period effects may also influence intervention effects. Moreover, the statistical analysis of split-mouth differs from that of parallel-arm 
RCTs because the paired nature of data must be taken into account [6-8]. Failure to consider the difference between the two types of trials may result in unreliable inference because the confidence interval for the true combined effect will be incorrect. Lesaffre et al. suggested that intervention effect estimates from split-mouth and parallel-arm RCTs may not be the same and recommended separate subgroup meta-analyses of split-mouth and parallel-arm RCTs to investigate systematic differences [9].

In this meta-epidemiological study, we aimed to assess if data from split-mouth RCTs were incorporated appropriately in meta-analyses and whether intervention effect estimates differ between split-mouth and parallel-arm RCTs in meta-analyses.

\section{Methods}

We performed a meta-epidemiological study to compare intervention effect estimates between split-mouth RCTs and parallel-arm RCTs. We identified meta-analyses that included at least one split-mouth RCT and at least one parallel-arm RCT assessing a variety of conditions and interventions on binary or continuous outcomes. For each selected meta- analysis, we compared intervention effect estimates between split-mouth and parallel-arm RCTs. In a second stage, results were summarized across all meta-analyses.

\section{Selection of meta-analyses, trials and outcomes}

To identify eligible studies, we searched MEDLINE and EMBASE. Search equations for each database included the free-text word "split mouth" combined with a filter designed to identify systematic reviews (see Additional file 1) [10]. Second, we performed a full-text search of the Cochrane Database of Systematic Reviews (CDSR) through www.thecochranelibrary.com and archie.cochrane.org. We also searched the Database of Abstracts of Reviews (DARE). Third, we searched SCIRUS, a science-specific search engine covering full-text articles. The last search was conducted in February 2013, with no restriction on date or language.

Two authors independently and in duplicate screened the titles and abstracts of records retrieved by the search, and then screened the selected full-text reports. When the designs of selected trials were unclear in an abstract, we always screened the full-text article. Any disagreements were resolved by discussion.

Eligible studies were systematic reviews of therapeutic or preventive interventions that included at least one split-mouth RCT, as labeled by the review authors, and at least one parallel-arm RCT in quantitative syntheses (ie, meta-analyses). Updates of systematic reviews were selected rather than initial versions.

From each eligible systematic review, we selected all independent meta-analyses (defined as the comparison between specific experimental and control interventions on a given outcome). We excluded meta-analyses in which all RCTs had a split-mouth or parallel-arm design. Then we selected one binary or one continuous outcome, or both if present, corresponding to the previous criteria. In cases of multiple eligible outcomes, we chose the primary outcome as stated by the authors or selected the outcome with the largest number of studies. For each meta-analysis, we selected all individual RCTs and we excluded non-randomized studies. Finally, we identified overlapping meta-analyses (ie, with common RCTs) and excluded the meta- analysis that included fewer trials [11].

\section{Data extraction}

Two authors extracted the data in duplicate and independently, with discrepancies resolved by discussion. For each systematic review, we recorded the first author, publication year and studied population. For each metaanalysis, we recorded the experimental intervention, the comparator, the outcome and the number of split-mouth and parallel-arm RCTs.

We assessed the methods used by the authors for incorporating split-mouth RCTs into meta- analyses: we assessed the presence of subgroup analyses (ie, splitmouth RCTs and parallel-arm RCTs analyzed separately) and/or whether one quantitative synthesis combined split-mouth and parallel-arm RCTs; in this case, we assessed whether the techniques described by Elbourne 2002 or Lesaffre 2009 were used [9,12]; moreover, we assessed whether the authors calculated the standard error of the intervention effect estimate in split- mouth RCTs using appropriate methods (ie, statistical approaches taking into account the paired nature of data; eg, the techniques described by Follmann) [13].

From the systematic review, for each RCT, we abstracted the first author and publication year and the design (split-mouth or parallel-arm). From the original RCT reports, we extracted the number of patients and, according to type of outcome, the means and associated SDs, or number of events, for both the experimental and control arms.

\section{Statistical analysis}

Binary and continuous outcomes were analyzed separately. For each RCT, we derived an intervention effect estimate and the associated sampling variance. Intervention effects were measured by odds ratios (ORs) and standardized mean differences (SMDs, or Cohen's d). All comparisons were coded so that the experimental intervention was compared with the comparator for an unfavorable outcome. Binary and continuous outcomes were coded so that an $\mathrm{OR}<1$ and $\mathrm{SMD}<0$ indicated a beneficial effect of the experimental intervention, respectively. For binary outcomes, in cases of 0-count cells, we 
used a 0.5 continuity correction. If no events occurred in all arms, the RCT was excluded.

For split-mouth RCTs, we took into account the matched nature of data; marginal ORs were calculated by the method of Becker and Balagtas [12,14,15]; SMDs were estimated by taking into account the within-patient correlation coefficient [16]. We contacted the corresponding authors of all split-mouth RCTs to ask for the required matched outcome data. If not available from the reports and with no response from authors, we assumed a within- patient correlation of 0.5 . Sensitivity analyses with correlation values of 0 and 0.25 yielded similar results.

For every meta-analysis, with more than one split-mouth or parallel-arm RCT, we calculated combined intervention effects and associated variances. We used both fixed-effects and random-effects (restricted maximum likelihood estimator) calculations. Results were similar, so we reported results obtained with fixed-effects primarily and those obtained with random-effects as sensitivity analysis.

We used a meta-epidemiological analysis to estimate the combined difference in intervention effect estimates between split-mouth and parallel-arm RCTs by a twostep method [17]. For each meta-analysis with a binary outcome, we estimated the ratio of the intervention effect for split-mouth RCTs to that for parallel-arm RCTs, the ratio of ORs (ROR): on a logarithmic scale, we derived $\log (\mathrm{ROR})=\log ($ summary OR in split-mouth RCTs) - log(summary OR in parallel-arm RCT) and its variance $\operatorname{Var}(\log R O R)=\operatorname{Var}[\log ($ summary OR in splitmouth RCTs) $+\operatorname{Var}[(\log$ summary OR in parallel-arm RCTs)]. Then we estimated a combined ROR and 95\% confidence interval (CI) across meta-analyses by a random-effects meta-analysis model (restricted maximum likelihood estimator). For each meta-analysis with a continuous outcome, we estimated the difference in intervention effect estimates between split-mouth and parallel-arm RCTs, the difference in SMDs $(\triangle \mathrm{SMD})$ : we derived $\triangle \mathrm{SMD}=$ summary SMD in split-mouth RCTs summary SMD in parallel-arm RCT and its variance Var $(\triangle \mathrm{SMD})=\operatorname{Var}[$ summary SMD in split-mouth RCTs] + $\operatorname{Var}[$ summary SMD in parallel-arm RCTs]. Then we estimated a combined $\triangle$ SMD across meta- analyses and 95\% CI across meta-analysis by a random-effects metaanalysis model (restricted maximum likelihood estimator). An $\mathrm{ROR}<1$ or $\triangle \mathrm{SMD}<0$ indicated that split-mouth $R C$ Ts yielded larger intervention effect estimates than parallel-arm RCTs. Heterogeneity in RORs or $\triangle$ SMDs across the different meta-analyses was assessed by the $\mathrm{I}^{2}$ statistic and $\operatorname{tau}^{2}$ the between-meta-analyses variance. We plotted the results on forest plots. We reported the 95\% prediction intervals for the ROR and $\triangle$ SMD, respectively, which provide a predicted range for the true difference in treatment effects between split-mouth and parallel-arm RCTs in an individual meta-analysis.
Analyses involved use of the $\mathrm{R}$ software (online at http://www.R-project.org, the R Foundation for Statistical Computing, Vienna,Austria). A 2-tailed $\mathrm{P}<0.05$ was considered statistically significant.

\section{Results}

\section{Eligible systematic reviews and meta-analyses}

The search yielded 335 potentially eligible articles. The flow chart of selection and reasons for exclusion are in Figure 1. We included 18 systematic reviews [18-36]; 8 were Cochrane systematic reviews [23,25-27,30,33,34,36]. The selected reviews were all published recently (range 2006 to 2013). The reviews concerned interventions for periodontal disease $(n=9)$, dental surgery/implantology $(n=6)$, dental caries $(n=2)$, and orthodontic treatment $(\mathrm{n}=1)$ (Table 1).

From the 18 systematic reviews, 42 meta-analyses were eligible. The identification of overlapping meta-analyses led to the exclusion of 8 meta-analyses (from 2 systematic reviews). Consequently, 34 meta-analyses contributed to our analysis: 15 with binary outcome data, and 19 with continuous outcome data. The median number of RCTs per meta- analysis was 4 (range 2-16) (Table 2).

\section{Methods used for incorporating split-mouth trials into meta-analyses}

In all systematic reviews, the authors combined splitmouth trials together with parallel-arm trials in metaanalyses (Table 3). For 6 of 18 systematic reviews, the authors also meta- analyzed split-mouth and parallelarm trials separately in subgroup analyses. Regarding the standard error of the intervention effect estimate in split-mouth RCTs, in 8 reviews, how the paired nature of data was taken into account was not clear and in another 8 reviews, the paired nature of data was imputed with methods described by Follmann [13] when the appropriate data were not present in RCT reports. Finally, we contacted the authors of all split-mouth RCTs to ask for the matched outcome data and we received 16 responses.

\section{Characteristics of split-mouth and parallel-arm trials}

The15 meta-analyses with binary outcome data involved 28 split-mouth and 28 parallel-arm RCTs; the19 metaanalyses with continuous outcome data involved 45 splitmouth and 48 parallel-arm RCTs, for 56 and 65 distinct split-mouth and parallel-arm RCTs, respectively. Parallelarm RCTs were published later than split-mouth RCTs (median [25\%-75\% percentile] 2007 [2002-2008] versus 2004 [1999-2008]); the first published RCT was a splitmouth RCT in 20 of the 34 meta-analyses. Parallel-arm RCTs had a larger median sample size than split-mouth RCTs (median 40 [29-90] versus 20 [12-30]). The median total relative weight of split-mouth RCTs in each metaanalysis was $51 \%$ [39-71\%] for the 34 meta-analyses. 


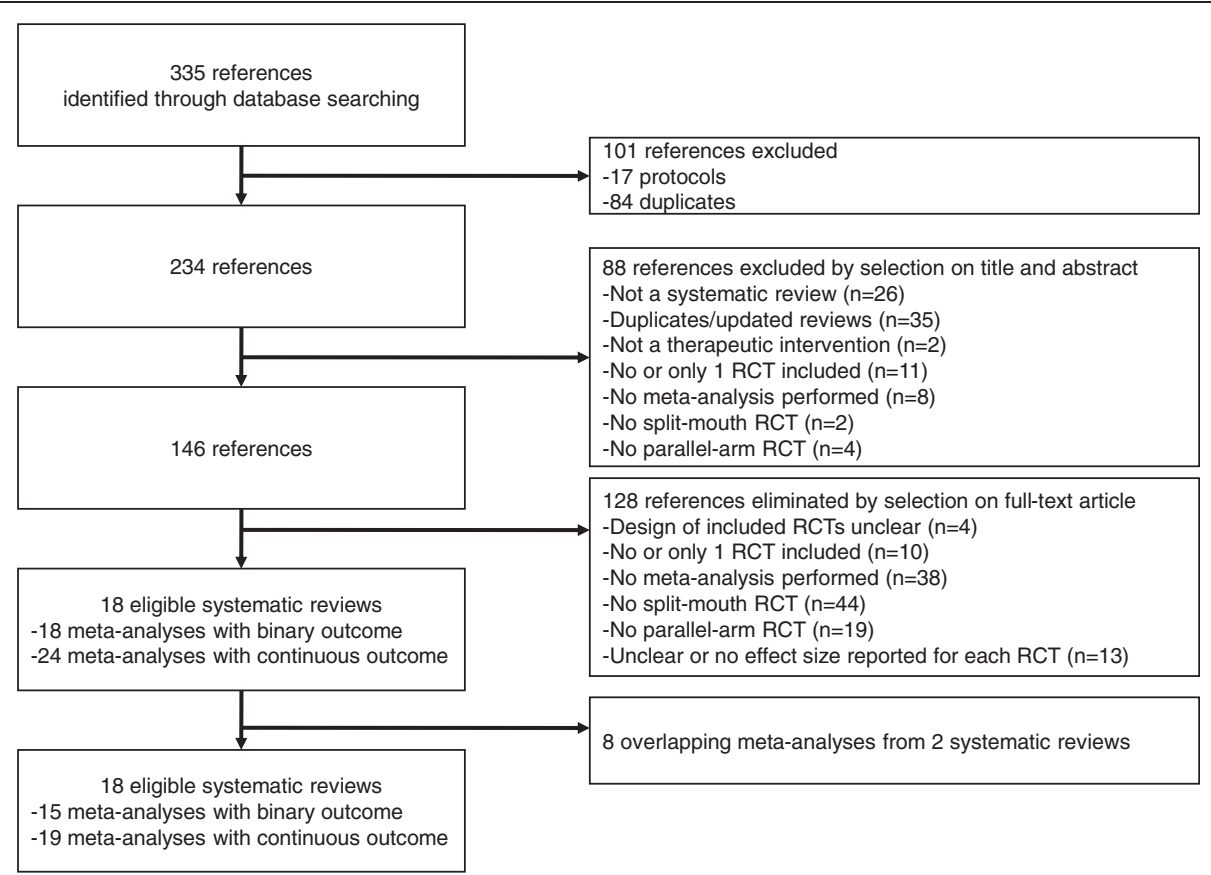

Figure 1 Flow diagram.

\section{Differences in intervention effect between split-mouth and parallel-arm trials}

Among the 15 meta-analyses with binary outcome data, 8 yielded a larger intervention effect for split-mouth RCTs (none with evidence for a difference between the two estimates) and 6 a larger intervention effect for parallelarm RCTs ( 2 with evidence for a difference between the two estimates) (see Additional file 2). Split-mouth and parallel-arm RCTs did not differ in intervention effect estimates: the meta-epidemiological analysis yielded a

\section{Table 118 selected systematic reviews}

\begin{tabular}{ll}
\hline Review & Population \\
\hline 1. Annibali [18] & Patients treated with dental implants \\
2. Atieh [19] & Patients with a clinical diagnosis of chronic periodontitis \\
3. Brignardello-Petersen [20] & Patients who underwent surgical removal of impacted mandibular third molars \\
4. Cairo [21] & Patients with a clinical diagnosis of Miller Class I or II localized gingival recession defect \\
5. Carrasco-Labra [22] & Healthy adult subjects who underwent surgical removal of an impacted mandibular third molar \\
6. Chambronne [23] & Patients with gingival recession areas (Miller's Class I or II $>3$ mm) \\
7. Del Fabbro [24] & Patients undergoing surgical procedures for the treatment of periodontal defects and gingival recession \\
8. Esposito [25] & Patients with osteointegrated root-form dental implants \\
9. Esposito [26] & Patients with chronic, aggressive, or early onset periodontitis and intrabony defects with an intrabony \\
10. Esposito [27] & component of at least 3 mm to be treated \\
11. Fleming [28] & Patients rehabilitated with implant supported/retained prostheses \\
12. Imai [29] & Patients with full-arch, fixed, and bonded orthodontic appliances \\
13. Lodi [30] & Adult patients with clinical signs of gingivitis and some periodontitis \\
14. Mickenautsch [31] & Patients undergoing tooth extraction for any indication \\
15. Muller-Bolla [32] & Patients requiring dental restoration \\
16. Needleman [33] & Patients $>5$ years old with permanent molars, all caries-free or with incipient carious lesions \\
17. Sgolastra [35] & Patients $\geq 21$ years old with chronic periodontitis or periodontitis \\
18. Yong [36] & Adult patients with chronic periodontitis \\
\hline
\end{tabular}


Table 235 selected meta-analyses (15 with binary outcomes and 19 with continuous outcomes)

\begin{tabular}{|c|c|c|c|c|}
\hline $\begin{array}{l}\text { Meta- } \\
\text { analysis }\end{array}$ & Experimental intervention & Comparator & Binary outcome & $\begin{array}{l}\text { Continuous } \\
\text { outcome }\end{array}$ \\
\hline 1 & Platform-switched implant restoration & Platform match & - & Marginal bone loss \\
\hline 2 & $\begin{array}{l}\text { Scaling and root planning + antimicrobial } \\
\text { photodynamic therapy }\end{array}$ & Scaling and root planning & - & $\begin{array}{l}\text { Clinical attachment } \\
\text { level gain }\end{array}$ \\
\hline 3. & Low-level laser energy irradiation & Nonactive comparator & - & Trismus \\
\hline 4.а. & $\begin{array}{l}\text { Coronally advanced flap + connective } \\
\text { tissue graft }\end{array}$ & Coronally advanced flap & Complete root coverage & $\begin{array}{l}\text { Gingival recession } \\
\text { change }\end{array}$ \\
\hline 4.b. & $\begin{array}{l}\text { Coronally advanced flap }+ \text { enamel } \\
\text { matrix derivative }\end{array}$ & Coronally advanced flap & Complete root coverage & $\begin{array}{l}\text { Gingival recession } \\
\text { change }\end{array}$ \\
\hline 4.c. & $\begin{array}{l}\text { Coronally advanced flap + acellular } \\
\text { dermal matrix }\end{array}$ & Coronally advanced flap & Complete root coverage & $\begin{array}{l}\text { Gingival recession } \\
\text { change }\end{array}$ \\
\hline 4.d. & $\begin{array}{l}\text { Coronally advanced flap + barrier } \\
\text { membranes }\end{array}$ & $\begin{array}{l}\text { Coronally advanced flap + connective } \\
\text { tissue graft }\end{array}$ & Complete root coverage & $\begin{array}{l}\text { Gingival recession } \\
\text { change }\end{array}$ \\
\hline 4.e & $\begin{array}{l}\text { Coronally advanced flap }+ \text { acellular } \\
\text { dermal matrix }\end{array}$ & $\begin{array}{l}\text { Coronally advanced flap + connective } \\
\text { tissue graft }\end{array}$ & Complete root coverage & $\begin{array}{l}\text { Gingival recession } \\
\text { change }\end{array}$ \\
\hline 5. & Secondary closure technique & Primary closure technique & Infectious complication & Pain \\
\hline 6.a & $\begin{array}{l}\text { Guided tissue regeneration }(\mathrm{rm})+\text { bone } \\
\text { substitutes }\end{array}$ & Subepithelial connective tissue grafts & - & $\begin{array}{l}\text { Gingival recession } \\
\text { change }\end{array}$ \\
\hline 6.b & $\begin{array}{l}\text { Guided tissue regeneration }(\mathrm{rm})+\text { bone } \\
\text { substitutes }\end{array}$ & Guided tissue regeneration (rm) & Complete root coverage & $\begin{array}{l}\text { Gingival recession } \\
\text { change }\end{array}$ \\
\hline 7. & Platelet-rich plasma & Control & - & $\begin{array}{l}\text { Clinical attachment } \\
\text { level gain }\end{array}$ \\
\hline 8.a & $\begin{array}{l}\text { Loading of osteointegreated implants } \\
\text { within } 1 \text { week }\end{array}$ & $\begin{array}{l}\text { Loading of osteointegreated implants } \\
\text { after } 2 \text { months }\end{array}$ & Prosthesis failure & $\begin{array}{l}\text { Marginal bone level } \\
\text { changes }\end{array}$ \\
\hline 8.b & $\begin{array}{l}\text { Loading of osteointegreated implants } \\
\text { within } 1 \text { week }\end{array}$ & $\begin{array}{l}\text { Loading of osteointegreated implants } \\
\text { between } 1 \text { week and } 2 \text { months }\end{array}$ & Prosthesis failure & $\begin{array}{l}\text { Marginal bone level } \\
\text { changes }\end{array}$ \\
\hline 9. & Emdogain & Control & $\begin{array}{l}\text { Probing attachment level } \\
\text { gain }<2 \mathrm{~mm}\end{array}$ & - \\
\hline 10. & Procedure with flap elevation & Flapless implant insertion & Implant failure & - \\
\hline 11. & 1-stage bonding (self-etch) & 2-stage bonding (acid-etch) & Bracket failure & - \\
\hline 12. & Dental floss & Interdental brushes & - & $\begin{array}{l}\text { Interproximal gingiva } \\
\text { bleeding }\end{array}$ \\
\hline 13. & Antibiotic - Pre-operative prophylaxis & Placebo & - & Pain \\
\hline 14. & Glass-ionomer cement & Amalgam & Caries & - \\
\hline 15.a & Fluoride-containing resin-based sealant & Light-cured resin-based sealant & Complete retention & - \\
\hline 15.b & Rubber dam & Cotton rolls & Complete retention & - \\
\hline 16 & Guided tissue regeneration & Control & - & $\begin{array}{l}\text { Clinical attachment } \\
\text { level gain }\end{array}$ \\
\hline 17. & $\begin{array}{l}\text { Scaling and root planning + Diode } \\
\text { laser }\end{array}$ & Scaling and root planning & - & $\begin{array}{l}\text { Probing depth } \\
\text { reduction }\end{array}$ \\
\hline 18. & Supplemental perioperative steroids & Placebo & - & $\begin{array}{l}\text { Systolic blood } \\
\text { pressure }\end{array}$ \\
\hline
\end{tabular}

rm: with resorbable membranes.

combined ROR of 0.96 (95\% CI $0.52-1.80, \mathrm{p}=0.91, \mathrm{I}^{2}=$ $50 \%$, 95\% CI $9 \%-80 \%$, and $\operatorname{tau}^{2}=0.62$ across metaanalyses) (Figure 2). The associated 95\% prediction interval for the ROR was 0.19 to 5.08. Finally, when using random-effects models for within-meta-analysis calculations of summary effect sizes in split-mouth and parallel-arm RCTs, it yielded a combined ROR of 0.79 (95\% CI 0.47-1.32, p = 0.36).
Among the 19 meta-analyses with continuous outcome data, 8 yielded a larger intervention effect for split-mouth RCTs ( 2 with evidence for a difference between the two estimates) and 9 a larger intervention effect for parallelarm RCTs (4 with evidence for a difference between the two estimates) (see Additional file 2). Split-mouth and parallel- arm RCTs did not differ in intervention effect estimates: the meta-epidemiological analysis yielded a 
Table 3 Methods used by review authors to incorporate split-mouth RCTs into meta-analyses

\begin{tabular}{|c|c|c|c|}
\hline \multirow[t]{2}{*}{ Review } & \multicolumn{2}{|c|}{$\begin{array}{l}\text { Split-mouth and parallel } \\
\text { arm RCTs combined }\end{array}$} & \multirow[t]{2}{*}{ Standard error of the treatment effect estimate in split-mouth RCTs } \\
\hline & Together & Separately (subgroups) & \\
\hline 1. Annibali [18] & Yes & Yes & Imputed using Follmann [13], with the appropriate data not presented \\
\hline 2. Atieh [19] & Yes & No & Not clear \\
\hline 3. Brignardello-Petersen [20] & Yes & Yes & Within-patient correlation assumed equal to 0 \\
\hline 4. Cairo [21] & Yes & No & Imputed using Follmann [13], with the appropriate data not presented \\
\hline 5. Carrasco-Labra [22] & Yes & Yes & $\begin{array}{l}\text { Imputed using Follmann [13], with the appropriate data not presented. } \\
\text { Within-patient correlation assumed equal to } 0.75\end{array}$ \\
\hline 6. Chambronne [23] & Yes & Yes & Imputed using Follmann [13], with the appropriate data not presented \\
\hline 7. Del Fabbro [24] & Yes & No & Not clear \\
\hline 8. Esposito [25] & Yes & No & Imputed using Follmann [13], with the appropriate data not presented \\
\hline 9. Esposito [26] & Yes & Yes & $\begin{array}{l}\text { Imputed using Follmann [13], with the appropriate data not presented. } \\
\text { Within-patient correlation assumed equal to } 0.25 \text { (median ICC in similar } \\
\text { review, Needleman [33]) }\end{array}$ \\
\hline 10. Esposito [27] & Yes & No & Imputed using Follmann [13], with the appropriate data not presented \\
\hline 11. Fleming [28] & Yes & No & Calculated using Borenstein [16] \\
\hline 12. Imai [29] & Yes & No & Not clear \\
\hline 13. Lodi [30] & Yes & No & Not clear \\
\hline 14. Mickenautsch [31] & Yes & No & Not clear \\
\hline 15. Muller-Bolla [32] & Yes & No & Not clear \\
\hline 16. Needleman [33] & Yes & Yes & $\begin{array}{l}\text { Imputed using Follmann [13], with the appropriate data not presented. } \\
\text { Within-patient correlation assumed equal to } 0.25\end{array}$ \\
\hline 17. Sgolastra [35] & Yes & No & Not clear \\
\hline 18. Yong [36] & Yes & No & Not clear \\
\hline
\end{tabular}

combined $\triangle$ SMD of 0.08 (95\% CI $-0.14-0.30, \mathrm{p}=0.46$, $\mathrm{I}^{2}=56 \%$, 95\% CI 21\%-82\%, and tau ${ }^{2}=0.12$ across metaanalyses) (Figure 3). The associated $95 \%$ prediction interval for the $\triangle \mathrm{SMD}$ was -0.63 to 0.79 . Finally, when using random-effects models for within-meta-analysis calculations of summary effect sizes in split-mouth and parallel-arm RCTs, it yielded a combined $\triangle$ SMD of 0.05 (95\% CI -0.21-0.30, $\mathrm{p}=0.73$ ).

In all, 6 of 8 meta-analyses showing differences between split-mouth and parallel-arm RCTs beyond chance did not meta-analyze split-mouth and parallel-arm RCTs separately in subgroup analyses.

\section{Discussion}

In our meta-epidemiological study, we found that splitmouth trials contributed half of the evidence in metaanalyses. Contrary to the recommendations by Lesaffre et al. and the Cochrane Oral Health group, most systematic reviews did not meta-analyze split-mouth and parallel-arm trials separately in subgroup analyses [37]. Moreover, most reviews did not report explicitly how split-mouth RCTs were handled in meta-analyses, while others approximated a paired analysis by imputing withinpatient correlations. Finally, our meta- epidemiological study did not provide sufficient evidence for a systematic difference in intervention effect estimates between splitmouth and parallel-arm RCTs, both for continuous and binary outcome data.

The main difference between split-mouth and parallelarm trials with regard to mechanisms of bias is that, in split-mouth trials, interventions may have effects on parts of the dentition other than those to which they were assigned; these carry-over effects put split-mouth trials at risk of bias. However, no method exists to assess or test the extent of carry-across effects in a split-mouth trial. As a consequence, the possibility of carry-over effects should be considered before deciding on whether a split-mouth design should be used. As far as we can judge a posteriori, the effects of interventions assessed in the reviews selected for our meta-epidemiological study were always localized.

Previous meta-epidemiological studies showed that individual study processes (eg, inadequate allocation concealment, non-blinding [38]) or nonprocess-related factors (eg, whether a study was conducted at a single center [39]) may put a randomized trial at risk of bias [40]. Very few meta-epidemiological studies have assessed if study designs itself could be associated with treatment effect estimates. Lathyris et al. focused on the crossover design, which is relevant to oral health research 


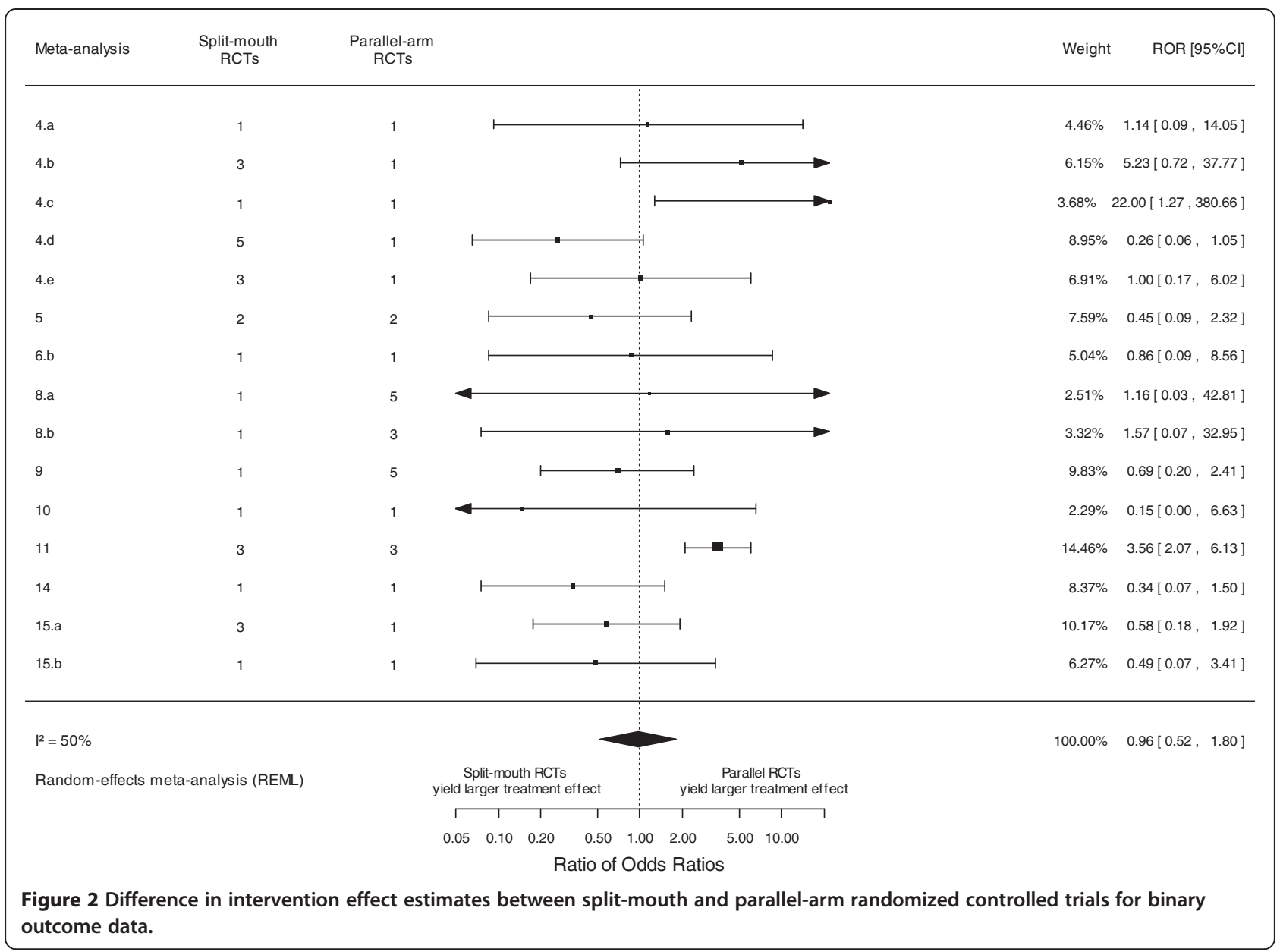

and biomedical research in general; the results of crossover trials tended to agree with those of parallel-arm trials [41]. Here, we focused on the split-mouth design, which is popular in oral health research. This type of design is in fact also relevant to other fields of biomedical research in general, in which split- body studies allocate the interventions to separate parts of the body of each participant. However, these trials are infrequent (about 2-3\% of randomized trials indexed in Pubmed) [42,43] and we could find only one meta-analysis including at least one split-body trial and at least one parallel-arm trial [44].

Our findings are based on recently published systematic reviews covering a fair range of conditions and interventions in oral healthcare. Consequently, our results are more generalizable than could be obtained with focus on a particular topic. Our study has several limitations. We selected a relatively small number of systematic reviews for our meta-epidemiological study. It is difficult to identify reviews with both parallel-arm and split-mouth trials with usual strategies and we acknowledge that unidentified reviews may exist. However, we systematically searched for both Cochrane and non-
Cochrane reviews, including a search of full-text articles indexed in the Cochrane library and in the Scirus database. Unfortunately, the latter service is no longer running. We acknowledge that searching additional regional databases (e.g., LILACS, PASCAL) and full-text databases (e.g., HighWire Press, Google Scholar) may be very useful to identify potentially eligible systematic reviews. Eligible reviews may be missing because of reporting bias (including location bias and language bias). However, reporting bias is usually driven by the magnitude/direction and statistical significance of treatment effects. We see no reason for reviews to be missing because of the difference in treatment effect estimates between split-mouth and parallel-arm RCTs. As a consequence, the impact of missing reviews is unpredictable and probably limited on our meta-epidemiological study. On top of the relatively small number of selected reviews, the number of split-mouth and parallel-arm RCTs in each meta-analysis was small. Meta-analyses typically include a limited number of trials: the median number of trials in a large sample of Cochrane meta- analyses was 3 [45]. The consequence is uncertainty in the difference between the 2 


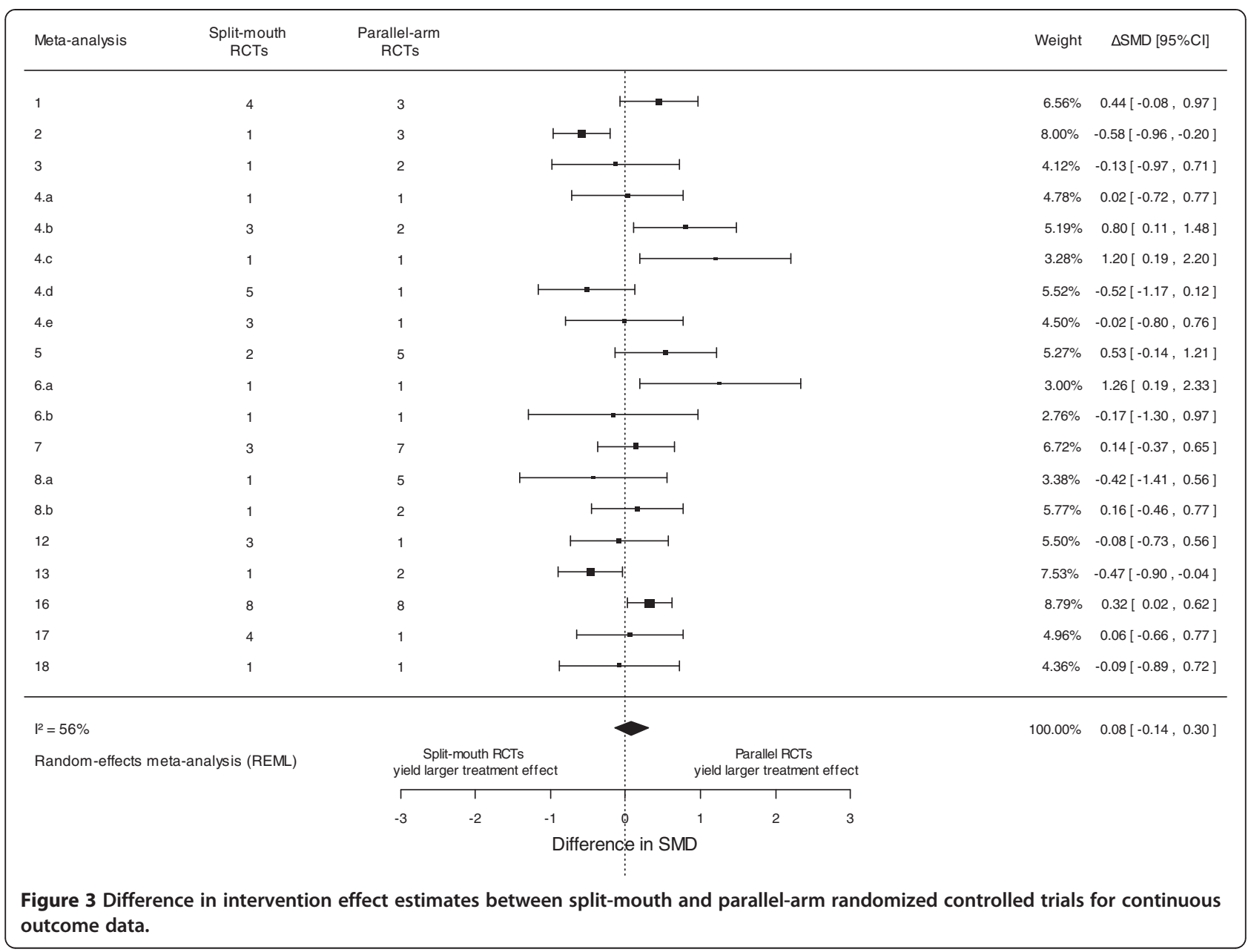

study designs. Because of these limitations, and as it is to our knowledge the first meta- epidemiological investigation on the subject, we acknowledge that these results should be replicated, by including additional comparisons between the two designs as they become available. A second caveat is that we did not assess risk of bias within each RCT and we cannot assess meta-confounding. The split-mouth and parallel-arm trials in the selected reviews may differ in their methodological quality. However, it would be difficult to assess the risk of bias in selected split-mouth trials because assessing internal validity requires adequate reporting and split-mouth trials frequently exhibit poor or inadequate reporting [37]. Moreover, meta-confounding because of systematic differences in risk of bias between split- mouth and parallel-arm trials would be an alternative explanation for an association between trial design and treatment effect estimates but we did not find evidence of such an association.

Our results support the use of all available evidence in systematic reviews, including that from split-mouth and parallel-arm RCTs, and authors should consider results from both trial designs in syntheses of oral health primary research. The incorporation of split-mouth RCTs should follow adequate methods [9,12]; moreover, for each split-mouth RCT, the difference between groups rather than estimates per group must be used and the standard error of the intervention effect estimate should take the matched nature of data into account [13].

Because trials in this field are frequently small, one should not be confident that the true intervention effect lies closer to the effect estimates from parallel-arm or split-mouth trials. Even when combining split-mouth and parallel-arm RCTs in the same meta-analysis, consideration should be given to potential differences between the different types of trials in subgroup analyses, until there is more evidence that the two designs do not systematically differ. Meta- analysts should also consider issues of external validity because split-mouth trials include patients with symmetrical caries or lesions who could differ from other patients in terms of possibly poorer brushing and dietary behavior. 


\section{Conclusions}

Our meta-epidemiological study did not provide sufficient evidence for a difference in intervention effect estimates derived from split-mouth and parallel-arm RCTs. Systematic review authors should consider including split-mouth RCTs in their meta-analyses with suitable and appropriate analysis.

\section{Additional files}

Additional file 1: Electronic search strategy.

Additional file 2: Comparisons of the summary ORs and SMDs between split-mouth and parallel-arm RCTs in each meta-analysis.

\section{Abbreviations}

RCT: Randomized controlled trial OR, Odds ratio; SMD: Standardized mean difference ROR, Ratio of odds ratios; $\triangle S M D$ : Difference in standardized mean differences $\mathrm{Cl}$, Confidence interval.

\section{Competing interests}

The authors declare that they have no competing interests.

\section{Authors' contributions}

VSF provided substantial contributions to conception and design of the study, data extraction, analysis and interpretation of data, drafted the article and revised it critically for important intellectual content. HFC provided substantial contributions to acquisition of data and interpretation of data, revised the article critically for important intellectual content. FC provided substantial contributions to interpretation of data and revised the article critically for important intellectual content. PD provided substantial contributions to conception and design of the study, interpretation of data and revised the article critically for important intellectual content. All authors read and approved the final manuscript.

\section{Acknowledgments}

We thank Laura Smales (BioMedEditing, Toronto, Canada) for editing the manuscript. We would like to thank the reviewers, Nikolaos Pandis, Spyridon Papageorgiou and Lesley Wood, for their helpful comments that improved this manuscript.

\section{Author details}

${ }^{1}$ Institut National de la Santé et de la Recherche Médicale, U1138, Equipe 22. Centre de Recherche des Cordeliers, Paris, France. ${ }^{2}$ Assistance Publique-Hôpitaux de Paris, Hôpital Bretonneau, Service d'Odontologie, Paris, France. ${ }^{3}$ Université Paris Descartes - Sorbonne Paris Cité, Faculté de Chirurgie Dentaire, Unité de Recherches Biomatériaux Innovants et Interface EA4462, Montrouge, France. ${ }^{4}$ Assistance Publique-Hôpitaux de Paris, Hôpital Charles Foix, Service d'Odontologie, Ivry- sur-Seine, France. ${ }^{5}$ Université Paris Descartes - Sorbonne Paris Cité, Faculté de Médecine, Paris, France.

${ }^{6}$ Département d'Informatique Hospitalière, Assistance Publique-Hôpitaux de Paris, Hôpital Européen Georges Pompidou, Paris, France. ${ }^{7}$ Unité de Recherches Biomatériaux Innovants et Interface EA4462, 1 rue Maurice Arnoux, Montrouge 92120, France.

Received: 24 January 2014 Accepted: 30 April 2014 Published: 11 May 2014

\section{References}

1. Antczak-Bouckoms AA, Tulloch JF, Berkey CS: Split-mouth and cross-over designs in dental research. J Clin Periodontol 1990, 17(7 Pt 1):446-453.

2. Pandis N, Walsh T, Polychronopoulou A, Katsaros C, Eliades T: Split-mouth designs in orthodontics: an overview with applications to orthodontic clinical trials. Eur J Orthod 2013, 35(6):783-789.

3. Ramfjord SP, Nissle RR, Shick RA, Cooper H Jr: Subgingival curettage versus surgical elimination of periodontal pockets. J Periodontol 1968, 39(3):167-175
4. Hujoel PP, DeRouen TA: Validity issues in split-mouth trials. J Clin Periodontol 1992, 19(9 Pt 1):625-627.

5. Hujoel PP, Loesche WJ: Efficiency of split-mouth designs. J Clin Periodontol 1990, 17(10):722-728.

6. Donner A, Eliasziw M: Application of matched pair procedures to site-specific data in periodontal research. J Clin Periodontol 1991, 18(10):755-759.

7. Hujoel PP: Design and analysis issues in split mouth clinical trials. Community Dent Oral Epidemiol 1998, 26(2):85-86.

8. Vaeth M, Poulsen S: Comments on a commentary: statistical evaluation of split mouth caries trials. Community Dent Oral Epidemiol 1998, 26(2):80-83. discussion 84.

9. Lesaffre E, Philstrom B, Needleman I, Worthington $\mathrm{H}$ : The design and analysis of split-mouth studies: what statisticians and clinicians should know. Stat Med 2009, 28(28):3470-3482.

10. Lee $E$, Dobbins M, Decorby K, McRae L, Tirilis D, Husson H: An optimal search filter for retrieving systematic reviews and meta-analyses. BMC Med Res Methodol 2012, 12:51.

11. Savović J, Harris RJ, Wood L, Beynon R, Altman D, Als-Nielsen B, Balk EM Deeks J, Gluud LL, Gluud C, John PA, loannidis JPA, Jüni P, Moher D, Pildal J, Kenneth F, Schulz KF, Sterne JAC: Development of a combined database for meta- epidemiological research. Res Synth Method 2010, 1(3-4):212-225.

12. Elbourne DR, Altman DG, Higgins JP, Curtin F, Worthington HV, Vail A: Meta- analyses involving cross-over trials: methodological issues. Int J Epidemiol 2002, 31(1):140-149.

13. Follmann D, Elliott $P$, Suh I, Cutler J: Variance imputation for overviews of clinical trials with continuous response. J Clin Epidemiol 1992, 45(7):769-773

14. Becker $M$, Balagtas $C$ : Marginal modelling of binary cross-over data. Biometrics 1993, 49(4):997-1009.

15. Stedman MR, Curtin F, Elbourne DR, Kesselheim AS, Brookhart MA Meta-analyses involving cross-over trials: methodological issues. Int J Epidemiol 2011, 40(6):1732-1734.

16. Borenstein $M$, Cooper $H$, Hedges $L$, Valentine J: Effect sizes for continuous data. In The Handbook of Research Synthesis and Meta-Analysis. Edited by Cooper H, Hedges L, Valentine J. New York: Russel Sage Foundation; 2009:221-235

17. Sterne JA, Juni P, Schulz KF, Altman DG, Bartlett C, Egger M: Statistical methods for assessing the influence of study characteristics on treatment effects in 'meta-epidemiological' research. Stat Med 2002, 21(11):1513-1524

18. Annibali S, Bignozzi I, Cristalli MP, Graziani F, La Monaca G, Polimeni A Peri- implant marginal bone level: a systematic review and meta-analysis of studies comparing platform switching versus conventionally restored implants. J Clin Periodontol 2012, 39(11):1097-1113.

19. Atieh MA: Photodynamic therapy as an adjunctive treatment for chronic periodontitis: a meta-analysis. Lasers Med Sci 2010, 25(4):605-613.

20. Brignardello-Petersen R, Carrasco-Labra A, Araya I, Yanine N, Beyene J, Shah $P$ : Is adjuvant laser therapy effective for preventing pain, swelling, and trismus after surgical removal of impacted mandibular third molars? a systematic review and meta-analysis. J Oral Maxillofac Surg 2012, 70(8):1789-1801.

21. Cairo F, Pagliaro U, Nieri M: Treatment of gingival recession with coronally advanced flap procedures: a systematic review. J Clin Periodontol 2008, 35(8):136-162

22. Carrasco-Labra A, Brignardello-Petersen R, Yanine N, Araya I, Guyatt G: Secondary versus primary closure techniques for the prevention of postoperative complications following removal of impacted mandibular third molars: a systematic review and meta-analysis of randomized controlled trials. J Oral Maxillofac Surg 2012, 70(8):e441-457.

23. Chambrone L, Sukekava F, Araujo MG, Pustiglioni FE, Chambrone LA, Lima LA Root coverage procedures for the treatment of localised recession-type defects. Cochrane Database Syst Rev 2009, 2, CD007161.

24. Del Fabbro M, Bortolin M, Taschieri S, Weinstein R: Is platelet concentrate advantageous for the surgical treatment of periodontal diseases? a systematic review and meta-analysis. J Periodontol 2011, 82(8):1100-1111.

25. Esposito M, Grusovin MG, Achille H, Coulthard P, Worthington HV: Interventions for replacing missing teeth: different times for loading dental implants. Cochrane Database Syst Rev 2009, 1, CD003878.

26. Esposito M, Grusovin MG, Papanikolaou N, Coulthard P, Worthington HV: Enamel matrix derivative (Emdogain(R)) for periodontal tissue 
regeneration in intrabony defects. Cochrane Database Syst Rev 2009, (4):CD003875

27. Esposito M, Maghaireh H, Grusovin MG, Ziounas I, Worthington HV: Interventions for replacing missing teeth: management of soft tissues for dental implants. Cochrane Database Syst Rev 2012, 2, CD006697.

28. Fleming PS, Johal A, Pandis N: Self-etch primers and conventional acid-etch technique for orthodontic bonding: a systematic review and meta-analysis. Am J Orthod Dentofacial Orthop 2012, 142(1):83-94.

29. Imai $P, Y u X$, MacDonald D: Comparison of interdental brush to dental floss for reduction of clinical parameters of periodontal disease: a systematic review. Can J Dental Hygiene 2012, 46(1):63-78.

30. Lodi G, Figini L, Sardella A, Carrassi A, Del Fabbro M, Furness S: Antibiotics to prevent complications following tooth extractions. Cochrane Database Syst Rev 2012, 11:CD003811.

31. Mickenautsch S, Yengopal V: Absence of carious lesions at margins of glass- ionomer cement and amalgam restorations: an update of systematic review evidence. BMC Res Notes 2011, 4:58.

32. Muller-Bolla M, Lupi-Pegurier L, Tardieu C, Velly AM, Antomarchi C: Retention of resin-based pit and fissure sealants: a systematic review. Community Dent Oral Epidemiol 2006, 34(5):321-336.

33. Needleman IG, Worthington HV, Giedrys-Leeper E, Tucker RJ: Guided tissue regeneration for periodontal infra-bony defects. Cochrane Database Syst Rev 2006, (2):CD001724.

34. Ricketts DN, Kidd EA, Innes N, Clarkson J: Complete or ultraconservative removal of decayed tissue in unfilled teeth. Cochrane Database Syst Rev 2006, (3):CD003808.

35. Sgolastra F, Severino M, Gatto R, Monaco A: Effectiveness of diode laser as adjunctive therapy to scaling root planning in the treatment of chronic periodontitis: a meta-analysis. Lasers Med Sci 2013, 28(5):1393-1402

36. Yong SL, Coulthard P, Wrzosek A: Supplemental perioperative steroids for surgical patients with adrenal insufficiency. Cochrane Database Syst Rev 2012, 12, CD005367.

37. Lesaffre E, Garcia Zattera MJ, Redmond C, Huber H, Needleman I: Reported methodological quality of split-mouth studies. J Clin Periodontol 2007, 34(9):756-761

38. Savovic J, Jones HE, Altman DG, Harris RJ, Juni P, Pildal J, Als-Nielsen B, Balk EM, Gluud C, Gluud LL, loannidis JP, Schultz KF, Beynon R, Welton NJ, Wood L, Moher D, Deeks JJ, Sterne JAC: Influence of reported study design characteristics on intervention effect estimates from randomized, controlled trials. Ann Intern Med 2012, 157(6):429-438.

39. Dechartres A, Boutron I, Trinquart L, Charles P, Ravaud P: Single-center trials show larger treatment effects than multicenter trials: evidence from a meta - epidemiologic study. Ann Intern Med 2011, 155(1):39-51.

40. Goodman S, Dickersin K: Metabias: a challenge for comparative effectiveness research. Ann Intern Med 2011, 155(1):61-62.

41. Lathyris DN, Trikalinos TA, loannidis JP: Evidence from crossover trials: empirical evaluation and comparison against parallel arm trials. Int J Epidemiol 2007, 36(2):422-430.

42. Chan AW, Altman DG: Epidemiology and reporting of randomised trials published in PubMed journals. Lancet 2005, 365(9465):1159-1162.

43. Hopewell S, Dutton S, Yu LM, Chan AW, Altman DG: The quality of reports of randomised trials in 2000 and 2006: comparative study of articles indexed in PubMed. BMJ 2010, 340:c723.

44. Greene D, Koch RJ, Goode RL: Efficacy of octyl-2-cyanoacrylate tissue glue in blepharoplasty: a prospective controlled study of wound-healing characteristics. Arch Facial Plast Surg 1999, 1(4):292-296.

45. Davey J, Turner RM, Clarke MJ, Higgins JP: Characteristics of meta-analyses and their component studies in the cochrane database of systematic reviews: a cross-sectional, descriptive analysis. BMC Med Res Methodol 2011, 11:160.

doi:10.1186/1471-2288-14-64

Cite this article as: Smail-Faugeron et al:: Comparison of intervention effects in split-mouth and parallel-arm randomized controlled trials: a meta-epidemiological study. BMC Medical Research Methodology 2014 14:64

\section{Submit your next manuscript to BioMed Central and take full advantage of:}

- Convenient online submission

- Thorough peer review

- No space constraints or color figure charges

- Immediate publication on acceptance

- Inclusion in PubMed, CAS, Scopus and Google Scholar

- Research which is freely available for redistribution

Submit your manuscript at www.biomedcentral.com/submit
C Biomed Central 